\title{
Prevalence and root causes of surgical site infections at an academic trauma and burn center in Ethiopia: a cross-sectional study
}

\author{
Rahel Mezemir ${ }^{1}$, Awole Seid² ${ }^{2}$ Teshome Gishu ${ }^{3}$, Tangut Demas ${ }^{1}$ and Addisu Gize ${ }^{4^{*}}$
}

\begin{abstract}
Background: Despite modern surgical techniques and the use of antibiotic prophylaxis, surgical site infection remains a burden for the patient and health system. It is a major cause of morbidity, prolonged hospital stay, and increased health costs. Thus, the main aim of this study was to determine the prevalence and root causes of surgical site infection among patients undergoing major surgery at an academic trauma and burn center in Ethiopia.

Methods: A hospital based cross-sectional study was conducted on 249 patients during 6-months' time window. Data entered in SPSS and multivariate logistic regression was employed to determine the root causes and the outcome variable.

Results: The prevalence of surgical site infection was found to be $24.6 \%$ of whom $10 \%$ develop deep site, $9.2 \%$ organ spaced and the remaining 5.2\% develop superficial space surgical site infection. The prevalence was high in patients who had undergone orthopedics (54.3\%) and abdominal (30\%) surgeries. Educational status, pre-morbid illness, duration of pre-operative and post-operative hospital stay, ASA score, and type of the wound were significantly associated with SSI at $p$-value of $\leq 0.05$. However, no association was found with BMI and location of the wound.

Conclusions: The prevalence of surgical site infection in the study population is still high. Preoperative hospital stay, pre-morbid illness, pre-operative and post-operative hospital stay, ASA score, and type of the wound were the independent predictors of surgical site infection. The duration of pre and post-operative periods should be kept to a minimum as much as possible. Patients with pre-morbid history of chronic diseases and contaminated wound require special attention to decrease the rate of occurrence of infections. In addition, longitudinal studies should be carried out to identify more risk factors.
\end{abstract}

Keywords: Prevalence, Surgical site infection, Addis Ababa, Ethiopia

\section{Background}

Surgical Site Infections (SSIs) are defined as infections apparent within 30 days of an operative procedure and most often between the 5th and 10th postoperative days. However, where a prosthetic implant is used, SSIs affecting the deeper tissues may occur several months after the operation [1].

\footnotetext{
* Correspondence: konjoaddisu@gmail.com; addisu.gize@sphmmc.edu.et ${ }^{4}$ Department Microbiology, St. Paul's Hospital Millennium Medical College, Addis Ababa, Ethiopia

Full list of author information is available at the end of the article
}

The risk of SSI is higher in developing countries relative to developed nations. SSI accounts for over $20 \%$ of all healthcare-associated infections in surgical patients. A large cross-sectional survey of healthcare-associated infections, conducted in mainland China in 2010, reported that E. coli (25.9\%), S. aureus (14.3\%), and P. aeruginosa $(11.9 \%)$ were the three most common pathogens associated with SSI [2].

The Centers for Disease Control and Prevention's (CDC's) National Healthcare Safety Network (NHSN) further classify SSIs as superficial incisional (involving only skin or subcutaneous tissue of the incision), deep

(C) The Author(s). 2020 Open Access This article is distributed under the terms of the Creative Commons Attribution 4.0 International License (http://creativecommons.org/licenses/by/4.0/), which permits unrestricted use, distribution, and 
incisional (involving fascia and/or muscular layers) and organ/space (involving any part of the body opened or manipulated during the procedure, excluding skin incision, fascia, or muscle layers) [3].

Most post-operative wound infections are hospital acquired and vary from one hospital to the other and even within a given hospital, and they are associated with increased morbidity and mortality [4]. The site of infection may be limited to the suture line or may become extensive in the operative site. The infecting microorganisms vary, depending on the type and location of surgery and antimicrobials received by the patient [5].

SSIs have been reported to be one of the most common causes of nosocomial infections; accounting for 20 to $25 \%$ of all nosocomial infections particularly in Ethiopia and generally in worldwide [6, 7]. SSIs have been responsible for increasing cost and morbidity and mortality related to surgical operations and continue to be a major problem worldwide [8]. Despite modern surgical techniques and the use of antibiotic prophylaxis, SSI is one of the most common complications encountered in surgery [1]. SSIs impose a substantial clinical burden. Surgical site infections will result for socioeconomic problem as they frequently result in hospital readmissions, expose for frequent surgeries, demanding long-term treatment, disability, and patient morbidity. Patients with SSIs are more likely to require readmission to hospital or intensive care unit (ICU) treatment, and are at higher risk of death, than those without such infections. Most of the time, it is associated with increased age, prolonged duration of hospital stay, blood transfusion and emergency surgery [9-11].

SSI places a significant burden on both the patient and health system especially in Sub Saharan Africa, where resources are limited and the average wound infection rates are 2 or 3 times higher than developed countries due to malnutrition, poor, and preoperative preparation [12]. Moreover, in developing countries where resources are limited, even basic life-saving operations, such as appendectomies and cesarean sections, are associated with high infection rates and mortality [13].

A study conducted on prevalence and predictors of surgical site infections among patients undergoing major surgery in Tanzania revealed its incidence is higher than that reported in developed countries. The overall surgical site infection rate was $26.0 \%$, of which $86.2 \%$ were superficial SSIs and $13.8 \%$ were deep SSIs. Regarding the predictors' pre-morbid illness, duration of operation, use of iodine alone for skin preparation, use of drain and cigarette smoking were significantly associated with SSIs [14].

In Ethiopia, the prevalence of SSI vary from hospital to hospital even from ward to ward and it ranges from $14.8-59 \%$ and also $6.5 \%$ from private hospitals up to $13.4 \%$ in public hospitals. In Addis Ababa it was reported $47 \%$ and in Gondar 39.5\%. Additionally, in Jimma University Specialized Hospital, the magnitude of clean contaminated and contaminated wound was 64.8 and $35.2 \%$, respectively [15-17].

Even though different researches were done in different part of Ethiopia, prevalence of SSI varies from hospital to hospital even from ward to ward. Thus, we are also interested to investigate to its prevalence and root causes in St Paul hospital which is one of the teaching hospitals delivering multiple services in the country. Additionally, this study will add knowledge regarding the root causes of the problem.

\section{Materials and methods}

A hospital based cross-sectional study was conducted prospectively from May1 to October 30, 2016. A total sample of 249 patients was recruited from St. Paul's Hospital Millennium Medical College (SPHMMC) and Addis Ababa Burn, Emergency and Trauma Hospital. More specifically, it was conducted in the surgical, orthopedic and maternity wards of these two affiliate hospitals. SPHMMC has currently 700 beds with an annual average of 200,000 patients and has a catchment population of more than 5 million. It is a semiindependent institution under SPHMMC, providing comprehensive emergency care in emergency medicine, critical care, orthopedics, neurosurgery and forensic medical services. The hospital has a capacity of 250 beds and can serve 50-60 emergency patients at a time with an additional 12 ICU beds.

All patients who underwent major surgical procedures with a visible incision at the respective study hospitals constitute the source population, and patients examined during the study period were considered the study population. Major surgery is defined as any invasive operative procedure in which a more extensive resection is performed and involves a risk to the life of the patient.

The sample size was computed using the single proportion population formula. By considering a maximum $17.9 \%$ estimated prevalence done in Addis Ababa, precision $(\mathrm{d}=0.05)$ and taking $95 \%$ confidence interval, it was estimated as 226 . By adding $10 \%$ non-response rate, the final sample size was calculated as $22+226=249$.

A proportional sample size was taken from General surgery $\left(\mathrm{n}_{1}=89\right)$, Orthopedic $\left(\mathrm{n}_{2}=80\right)$, Gynecology and Obstetrics $\left(\mathrm{n}_{3}=50\right)$ and ENT $\left(\mathrm{n}_{4}=30\right)$. Additionally, taking a list of post-operative patients as a sampling frame, systematic random sampling technique with $\mathrm{k}=4$ were employed to select these study subjects.

A diagnosis of a deep incisional SSI was confirmed by a surgeon or attending physician. The Centers for Diseases Control and Prevention (CDC) and National Nosocomial Infection Surveillance (NNIS) system criteria and method were used for identifying and diagnosing SSI. 
Patients who showed signs and symptoms of infection within the first $48 \mathrm{~h}$ of admission were excluded from the study. Data was collected from post-operative patients who stayed for $48 \mathrm{~h}$ after surgery and before discharge. The denominator used to determine the rate was all moribund patients who are not expected to survive without the operation and underwent major surgery.

Each eligible patient was followed from the time of admission until time of discharge using a well-structured questionnaire. The data collection tool captured sociodemographic data and relevant clinical characteristics related to SSIs. Seven BSc nurses and two general practitioners (GPs) were recruited as data collectors and supervisors, respectively.

After data collection, each questionnaire was checked for completeness. Data was coded, cleaned, and analyzed using SPSS version 20. Logistic regression was used in order to test association between independent and dependent variables. Odds Ratio, 95\% CI P-value < 0.05 was used to test associations.

Ethical clearance was obtained from the review board of SPHMMC. After the purpose and objective of the study were explained, verbal consent was obtained from each study subject and confidentiality was maintained. Participants were also informed that participation was on a voluntary basis.

\section{Result}

A total of 249 admitted patients for major surgical procedures were studied and the response rate was $100 \%$.

\section{Socio-demographic characteristics}

Of the 249 samples, $40.2 \%$ were males and the rest (59.8\%) were females. The mean age of study participants was 25 years $( \pm$ SD 1.01) and $30.9 \%$ of the respondents were in the age range of 25-34 years. One hundred forty eight (59.4\%) patients come from out of Addis Ababa, 67.5\% Orthodox in religion, and 69.9\% of participants were married. A substantial proportion (71.5\%) had a BMI of $18-25 \mathrm{k} . \mathrm{g} / \mathrm{m}^{2}$ which is normal weight. The educational status of respondents showed $38.6 \%$ completed primary school.

Concerning the length of post-operative admission, the range varied between below 3 up to 60 days. A majority of post-operated patients (34\%) stayed in the hospital for 3-8 days.

Regarding other clinical variables, 51(25.4\%) of infected patients had ASA score of I, and $26.1 \%$ of major surgeries were performed using general anesthesia. Most surgeries lasted less than $2 \mathrm{~h}$. Of patients who stayed above $4 \mathrm{~h}$ pre-operatively, $38.1 \%$ develop SSIs (Table 1).

\section{Prevalence of surgical site infection and other clinical variables}

In this study the overall prevalence of surgical site infection was found to be $24.5 \%$. Moreover, the prevalence of surgical site infection was high in orthopedics and abdominal surgery which accounts 54.3 and 30\% respectively and least documented in bladder surgery and cholelithiasis.

Most of the operations were elective (56.6\%) and the rest $(43.4 \%)$ were emergencies. Two hundred $(80.3 \%)$ respondents had no pre-morbid conditions.

Regarding the duration of operation, it ranged from 0 to $2 \mathrm{~h}$. The SSI rate in patients with duration of operation $<1 \mathrm{~h}$ was $20.8 \%$ as compared to $34.3 \%$ in above $\geq 2 \mathrm{~h}$.

The proportion of SSI based on location of wound showed wound on back 1(16.7\%), abdomen 24 (14.9\%), neck and head 9 (34.6\%) and leg 14(63.6\%). Moreover, $198(79.5 \%)$ of participants took antibiotics before surgery.

A significant number of patients developed deep surgical site infection (10\%), 9.2\% developed organ spaced, and the least one $5.2 \%$ developed superficial space SSI.

\section{Factors associated with surgical site infection}

Multivariate logistic regression analysis results showed educational status, pre-morbid illness, pre-operative and post-operative hospital stay, ASA score, and the type of wound were found to be significantly associated with SSI at $p$-value of $\leq 0.05$.

In this study, respondents with higher education were 0.1 times [AOR: $0.1(0.03-0.91, p=0.041)$ ] less likely to predispose to SSI as compared to illiterates. On the other hand, patients who stayed $>4 \mathrm{~h}$ pre-operatively were 6 times more likely to develop surgical site infection as compared to < $2 \mathrm{~h}$ [AOR: $6(1.5-27.9, p=0.012)]$.

Regarding the length of post-operative stay after surgery, participants admitted for 7-14 and $>14$ days were 5 times more likely to acquire surgical SSI than $<7$ days [AOR: 4.3(1.11-16.10), $P=0.035]$, [AOR: 5(2.04-101.12, $p=0.007)$ ] respectively.

Concerning the surgical site wound category, the clean-contaminated wound category was about 6 times [AOR: 6(5.39-35.94), $p=0.000$ ] more likely to increase the risk of SSI as compared to a clean wound.

American Society of Anesthesiology (ASA) Class I patients were 0.3 times less likely to develop surgical site infection than patients with severe systemic disease (Class III) ([AOR: 0.03(0.07-1.26)] (Table 2).

\section{Discussion}

In the present investigation, SSI was observed in $24.6 \%$ of patients. Even though many hospitals in Ethiopia are planning to have zero SSI, it has continued to be a drawback of quality of surgical care. This finding was lower than the study conducted in Ethiopia at Tikur Anbessa 
Table 1 Socio-demographic characteristics and clinical variables of respondents who developed surgical site infection after surgery, 2016, Addis Ababa, Ethiopia

\begin{tabular}{|c|c|c|c|c|}
\hline \multirow[t]{2}{*}{ Characteristics } & & \multicolumn{3}{|c|}{ SSI Infection status } \\
\hline & & Infected $N(\%)$ & Non-infected N (\%) & Total \\
\hline \multirow[t]{4}{*}{ Age (years) } & $18-24$ & $7(14.3 \%)$ & $42(85.7 \%)$ & $49(100 \%)$ \\
\hline & $24-34$ & $15(19.5 \%)$ & $62(80.5 \%)$ & 77 (100\%) \\
\hline & $35-60$ & $23(30.3)$ & $53(69.7 \%)$ & 76 (100\%) \\
\hline & $>60$ & $16(34 \%)$ & $31(66 \%)$ & $47(100 \%)$ \\
\hline \multirow[t]{2}{*}{ Sex } & Male & $30(30 \%)$ & $70(70 \%)$ & $100(100 \%)$ \\
\hline & Female & $31(20.8)$ & $118(79.2)$ & 149 (100\%) \\
\hline \multirow[t]{3}{*}{ Religion } & Orthodox Christian & $42(25 \%)$ & $126(75 \%)$ & $168(100 \%)$ \\
\hline & Muslim & $13(26 \%)$ & $37(74 \%)$ & 50 (100\%) \\
\hline & Protestant & $6(19 \%)$ & $25(80.6 \%)$ & $31(100 \%)$ \\
\hline \multirow[t]{4}{*}{ Residence } & Addis Ababa & $27(26.7 \%)$ & $74(73.3 \%)$ & $148(100 \%)$ \\
\hline & Out of Addis Ababa & $34(23 \%)$ & $114(77 \%)$ & $101(100 \%)$ \\
\hline & Single & $16(27.1)$ & $43(72.9 \%)$ & $59(100 \%)$ \\
\hline & Married & $42(24.1)$ & $132(75.9 \%)$ & $174(100 \%)$ \\
\hline \multirow[t]{3}{*}{ Marital status } & Divorced & $2(28.6 \%)$ & $5(71.4 \%)$ & $7(100 \%)$ \\
\hline & Widowed & $1(11.1 \%)$ & $8(88.9 \%)$ & $9(100 \%)$ \\
\hline & Illiterate & $20(37 \%)$ & $34(63 \%)$ & $54(100 \%)$ \\
\hline \multirow[t]{4}{*}{ Education } & Primary school & 19 (19.8) & 77 (80.2\%) & $96(100 \%)$ \\
\hline & Secondary school & $17(25 \%)$ & $51(75 \%)$ & $68(100 \%)$ \\
\hline & Higher Education & $5(16.1 \%)$ & $26(83.9 \%)$ & $31(100 \%)$ \\
\hline & Under weight $(<18)$ & $10(52.6 \%)$ & $9(47.4 \%)$ & 19 (100\%) \\
\hline \multirow[t]{3}{*}{$\mathrm{BMI}\left(\mathrm{kg} / \mathrm{m}^{2}\right)$} & normal weight(18-25) & $40(22.5 \%)$ & $138(77.5 \%)$ & $178(100 \%)$ \\
\hline & Overweight (26-29) & $11(21.2 \%)$ & $41(78.5 \%)$ & $52(100 \%)$ \\
\hline & 1 & $51(25.4 \%)$ & $150(74.6 \%)$ & $201(100 \%)$ \\
\hline \multirow[t]{2}{*}{ ASA scoring } & $\|$ & $6(14.3 \%)$ & $36(85.7 \%)$ & $42(100 \%)$ \\
\hline & III & $4(66,7 \%)$ & $2(33.3 \%)$ & $6(100 \%)$ \\
\hline \multirow[t]{3}{*}{ Type of Anesthesia } & General anesthesia & $46(26.1 \%)$ & $130(73.9 \%)$ & $176(100 \%)$ \\
\hline & Spinal anesthesia & $15(20.5 \%)$ & $58(79.5 \%)$ & $73(100 \%)$ \\
\hline & $<2 h$ & 25 (20.9\%) & $95(79.2 \%)$ & $120(100 \%)$ \\
\hline \multirow[t]{2}{*}{ Intra-operation duration } & $1-2 h$ & $24(25.5 \%)$ & $70(74.5 \%)$ & $94(100 \%)$ \\
\hline & $>2 h$ & $12(34.3 \%)$ & $23(65.7 \%)$ & $35(100 \%)$ \\
\hline \multirow[t]{3}{*}{ Pre-operative hospital stay } & $<2 \mathrm{~h}$ & $30(19 \%)$ & $128(81 \%)$ & $158(100 \%)$ \\
\hline & 2 to $4 \mathrm{~h}$ & 15 (30.6\%) & $34(69.4 \%)$ & 49 (100\%) \\
\hline & $>4 h$ & $16(38.1 \%)$ & $26(61.4 \%)$ & $42(100 \%)$ \\
\hline \multirow[t]{3}{*}{ Wound Classification } & Clean & 0 & $125(100 \%)$ & $125(100 \%)$ \\
\hline & Clean-contaminated & $48(43.6 \%)$ & $62(56.4 \%)$ & $110(100 \%)$ \\
\hline & Contaminated & $7(50 \%)$ & $7(50 \%)$ & $14(100 \%)$ \\
\hline
\end{tabular}

Hospital, Addis Ababa (47 to 59\%) [15, 16]. The previous study was conducted far earlier, so there might be different improvements today. Similar findings were found in Tanzania 19.4\%, Albania 24.3\%, Norway, 28\%. However, the prevalence is higher than studies conducted in other hospitals of Ethiopia, such as in Felege
Hiwot Referral Hospital, 10.2\%, [18] and in Gondar University Teaching Hospital 3.5\% [17]. The high prevalence in our study might be attributable to:

1. Inefficient infection control practice in the hospital and inadequate environmental hygiene; 
Table 2 Multivariate analysis of factors associated with SSI in 2016, Addis Ababa, Ethiopia

\begin{tabular}{|c|c|c|c|c|}
\hline Characteristic & Patients with SSI & Patients without SSI & AOR $(95 \% \mathrm{Cl})$ & P-value \\
\hline \multicolumn{5}{|l|}{ Educational Status } \\
\hline Illiterate & $20(37 \%)$ & $34(63 \%)$ & 1 & \\
\hline Grade 1-8th & 19 (19.8) & 77 (80.2\%) & & \\
\hline Grade 9-12th & $17(25 \%)$ & $51(75 \%)$ & & \\
\hline College/university & $5(16.1 \%)$ & $26(83.9 \%)$ & $0.1(0.03-0.913)$ & 0.041 \\
\hline \multicolumn{5}{|c|}{ Pre-operative hospital stay } \\
\hline$<2 h$ & 30 (19\%) & $128(81 \%)$ & 1 & \\
\hline $2-4 h$ & $15(30.6 \%)$ & $34(69.4 \%)$ & & \\
\hline$>4 \mathrm{~h}$ & $16(38.1 \%)$ & $26(61.4 \%)$ & $6(1.5-27.90)$ & 0.012 \\
\hline \multicolumn{5}{|c|}{ Post-operative hospital stay } \\
\hline$<7$ days & $34(55.7 \%)$ & $169(89.9 \%)$ & 1 & \\
\hline 7-14 days & $14(23 \%)$ & $13(6.9 \%)$ & $4.3(1.11-16.10)$ & 0.035 \\
\hline$>14$ days & $13(21.3 \%)$ & $6(3.2 \%)$ & $5(2.04-101.12)$ & 0.007 \\
\hline \multicolumn{5}{|l|}{ ASA score } \\
\hline III & $4(66.7 \%)$ & $2(33.3 \%)$ & 1 & \\
\hline$\|$ & $6(14.3 \%)$ & $36(85.7 \%)$ & & \\
\hline । & $51(25.4 \%)$ & $150(74.6 \%)$ & $0.3(0.07-1.26)$ & 0.026 \\
\hline \multicolumn{5}{|l|}{ Pre-morbid illness } \\
\hline Diabetes Mellitus & $5(62.5 \%)$ & $3(37.5 \%)$ & 1 & \\
\hline Hypertension & $3(10.7 \%)$ & $25(89.3 \%)$ & $0.03(0.001-0.74)$ & 0.032 \\
\hline HIV & 0 & $4(100 \%)$ & & \\
\hline No disease & $50(25 \%)$ & $150(75 \%)$ & $0.002(0.00-0.13)$ & 0.003 \\
\hline \multicolumn{5}{|l|}{ Wound classification } \\
\hline Clean & 0 & $125(100 \%)$ & 1 & \\
\hline Clean-contaminated & $48(43.6 \%)$ & $62(56.4 \%)$ & $5(4.80-93.95)$ & $<0.001$ \\
\hline Contaminated & $7(50 \%)$ & $7(50 \%)$ & $6(5.39-35.94)$ & $<0.001$ \\
\hline
\end{tabular}

2. Number of people in theatre may be increased as it is a teaching hospital;

3. Other studies evaluated only one or two wards which might underestimate their results.

A meta-analysis report of mainland China showed the average incidence of SSI was 4.5\% (95\% CI: 3.1-5.8) analyzed from 2001 to 2012. This far lower figure shows that health care associated infections continued to be a threat for surgical care in Ethiopia [2].

Furthermore, in this study educational status, prehospital stay, duration of post-operative admission, premorbid status, ASA score of the wound, and type of wound were significantly associated with surgical site infection. These findings are also similar in a study reporting from Felege Hiwot Referral Hospital [18], Pakistan [19], and Nigeria [20]. However, BMI, age, and sex were not associated.

Previous studies have shown that patients with premorbid illnesses, such as diabetes mellitus, are at a higher risk of developing SSI due to their low immunity [14]. This study also shows patients who are co-morbid with diabetes have a higher rate developing infection as compared to hypertensive patients. However, the number of HIV infected patients was not enough to conduct association tests.

The multivariate logistic regression analysis finding showed that the rate of SSI was significantly associated with ASA classification. Similar findings have been reported by other studies [21]. In this study, ASA class 1 decreased the risk for SSIs by 0.3 times as compared to ASA 3 .

Moreover, surgeries performed on contaminated wounds increase the rate of infection by 6 fold, which necessitates careful assessment of the nature of wound before surgery.

The limitation of this study could be an underestimation of the prevalence of SSI because many of these infections occur after the patient has been discharged from hospital. Besides, the research is not supported with culture investigation, which is done by other 
studies, so that there might be underestimation or overestimation of the prevalence.

\section{Conclusion}

The prevalence of SSI in the study area is still high and requires due attention. Consistent infection prevention practices with commitments of the higher officials and policy makers have to be implemented in the institution. Furthermore, as it is a teaching institution, the number of students in the operating theater should be minimized as much as possible to reduce the risk of infection.

Post operation hospital stay, prolonged preoperative hospital stay, pre-morbid conditions, and contaminated and dirty wound classes were the independent predictors of SSIs.

The duration of pre- and post-operative periods should be kept to the minimum as much as possible. Patients with a pre-morbid history of chronic diseases and contaminated wounds require special attention to decrease the rate of occurrence of infections.

A longitudinal study with sound methodology should be conducted to identify more risk factors.

\section{Abbreviations}

ASA: American Society of Anesthesiology; CDC: Center for Disease Control and Prevention; ICU: Intensive Care Unit; NNISS: National Nosocomial Infection Surveillance System; SSI: Surgical Site Infection; WHO: World Health Organization

\section{Acknowledgements}

We would like to give our thanks to St. Paul's Hospital and Millennium Medical College for funding the research project and our heartfelt gratitude also extends to data collectors and respected study participants.

\section{Authors' contributions \\ RM initiated the idea, carried out the study, and involved in drafting the manuscript. AS contributed to the statistical analysis and in preparing the manuscript. TG and TD contributed to the entry, analysis, critically revised the paper and provided the final version. AG edits starting from the proposal development up to the final manuscript writing and critically reviewed the manuscript for intellectual content. All authors read and approved the final manuscript.}

\section{Funding}

The entire funding to conduct this study was provided by St. Paul's Hospital and Millennium Medical College, Addis Ababa, Ethiopia.

\section{Availability of data and materials}

All data generated or analyzed during this study are included in this published article.

\section{Ethics approval and consent to participate}

In order to keep the ethical soundness of the research, an ethical approval letter was obtained from the Institutional Review Board (IRB) of St. Paul's Hospital and Millennium Medical College. Verbal consent was also secured before data collection.

\section{Consent for publication}

Not applicable.

\section{Competing interests}

The authors declare that they have no competing interests.

\section{Author details}

'Department of Surgical Nursing, St. Paul's Hospital Millennium Medical College, Addis Ababa, Ethiopia. '2Department of Adult Health Nursing, Bahir Dar University, Bahir Dar, Ethiopia. ${ }^{3}$ Department of Emergency Medicine and Critical Care Nursing, St. Paul's Hospital Millennium Medical College, Addis Ababa, Ethiopia. ${ }^{4}$ Department Microbiology, St. Paul's Hospital Millennium Medical College, Addis Ababa, Ethiopia.

Received: 3 September 2019 Accepted: 30 December 2019

Published online: 07 January 2020

\section{References}

1. National Collaborating Centre for Women's and Children's Health. Surgical site infection prevention and treatment of surgical site infection: Clinical Guideline. NICE (2008); Available at: http://www.nice.org.uk/nicemedia/pdf/ CG74FullGuideline.pdf

2. Fan $Y$, Wei $Z$, Wang $W$, Tan $L$, Jiang $H$, Tian $L$, et al. The incidence and distribution of surgical site infection in mainland China: a meta-analysis of 84 prospective observational studies. Sci Rep. 2014;4:1-8.

3. Centers for Disease Control and Prevention. National Healthcare Safety Network. Surgical Site Infection Event. 2010; Available at: http://www.cdc. gov/nhsn/pdfs/pscmanual/9pscssicurrent.pdf.

4. Isibor JO, Oseni A, Eyaufe A, Turay A. Incidence of aerobic bacteria and Candida albicans in post-operative wound infections. Afr J Microbiol Res. 2008;2(11):288-91.

5. Bereket W, Hemalatha K, Getenet B, Wondwossen T, Solomon A, Zeynudin A, et al. Update on bacterial nosocomial infections. Eur Rev Med Pharmacol Sci. 2012;16(8):1039-44.

6. Mamo T, Abebe TW, Chichiabellu TY, Anjulo AA. Risk factors for surgical site infections in obstetrics: a retrospective study in an Ethiopian referral hospital. Patient Saf Surg. 2017;11(1):24

7. Control CD. Prevention. Sexually transmitted diseases treatment guidelines, 2010. Ann Emerg Med. 2011;58(1):67-8.

8. Dalhatu A, Olaogun A, Olayinka AT, Ahmed S, Timothy G, Yunusa U. Incidence of Surgical Site Infections (SSIs) among Patients Undergoing Major Surgery at General Hospital Funtua, Katsina State, Nigeria. IOSR Journal of Nursing and Health Science. 2014;3(3):16-21 www. iosrjournals.org.

9. Zelle BA, Stahel PF. Lessons learned for postoperative wound healing: respect the past and embrace the future. Patient Saf Surg. 2019;13(1):5.

10. Mukagendaneza MJ, Munyaneza E, Muhawenayo E, Nyirasebura D, Abahuje E, Nyirigira J, et al. Incidence, root causes, and outcomes of surgical site infections in a tertiary care hospital in Rwanda: a prospective observational cohort study. Patient Saf Surg. 2019;13(1):10.

11. Handaya AY, Werdana VAP. Adherence to preoperative hand hygiene and sterile gowning technique among consultant surgeons, surgical residents, and nurses: a pilot study at an academic medical center in Indonesia. Patient Saf Surg. 2019;13(1):11.

12. Gelaw KA, Aweke AM, Astawesegn FH, Demissie BW, Zeleke LB. Surgical site infection and its associated factors following cesarean section: a cross sectional study from a public hospital in Ethiopia. Patient Saf Surg. 2017; 11(1):18.

13. Gaynes RP, Culver DH, Horan TC, Edwards JR, Richards C, Tolson JS, et al. Surgical site infection (SSI) rates in the United States, 1992-1998: the National Nosocomial Infections Surveillance System basic SSI risk index. Clin Infect Dis. 2001:33(Supplement 2):S69-77.

14. Mawalla B, Mshana SE, Chalya PL, Imirzalioglu C, Mahalu W. Predictors of surgical site infections among patients undergoing major surgery at Bugando medical Centre in Northwestern Tanzania. BMC Surg. 2011; 11(1):21.

15. Fisha K, Azage M, Mulat G, Tamirat KS. The prevalence and root causes of surgical site infections in public versus private hospitals in Ethiopia: a retrospective observational cohort study. Patient Saf Surg. 2019;13(1):26.

16. Amenu D, Belachew T, Araya F. Surgical site infection rate and risk factors among obstetric cases of Jimma University specialized hospital, Southwest Ethiopia. Ethiop J Health Sci. 2011;21(2):91-100.

17. Amare B, Abdurrahman Z, Moges B, Ali J, Muluken L, Alemayehu M, et al. Postoperative surgical site bacterial infections and drug susceptibility patterns at Gondar University teaching hospital, Northwest Ethiopia. J Bacteriol Parasitol. 2011;2(8):126. 
18. Mulu W, Kibru G, Beyene G, Damtie M. Postoperative nosocomial infections and antimicrobial resistance pattern of bacteria isolates among patients admitted at Felege Hiwot referral hospital, Bahirdar, Ethiopia. Ethiop J Health Sci. 2012;22(1):7-18.

19. Bibi S, Channa GA, Siddiqui TR, Ahmed W. Frequency and risk factors of surgical site infections in general surgery ward of a tertiary care hospital of Karachi, Pakistan. Int J Infect Control. 2011;7(3):1-5.

20. Adejumo AA, Nuhu M, Afolaranmi T. Incidence of and risk factors for abdominal surgical site infection in a Nigerian tertiary care centre. Int J Infect Control. 2015;11(4):12-1.

21. Kalmeijer MD, van Nieuwland-Bollen E, Bogaers-Hofman D, de Baere GA, Kluytmans JA. Nasal carriage of Staphylococcus aureus: is a major risk factor for surgical-site infections in orthopedic surgery. Infect Control Hosp Epidemiol. 2000;21(5):319-23.

\section{Publisher's Note}

Springer Nature remains neutral with regard to jurisdictional claims in published maps and institutional affiliations.

Ready to submit your research? Choose BMC and benefit from:

- fast, convenient online submission

- thorough peer review by experienced researchers in your field

- rapid publication on acceptance

- support for research data, including large and complex data types

- gold Open Access which fosters wider collaboration and increased citations

- maximum visibility for your research: over $100 \mathrm{M}$ website views per year

At BMC, research is always in progress.

Learn more biomedcentral.com/submissions 